\title{
Semantic Web Technologies for the Reuse and Adaptation Of Educational Documents in E-Learning
}

http://dx.doi.org/10.3991/ijep.v3i1.2167

\author{
CHEKRY Abderrahman and KHALDI Mohamed \\ Abdelmalek Essaâdi University, Tetwan, Morocco
}

\begin{abstract}
This work is about adapting the content of learning with learner's preferences, and gives the teachers the ability to reuse a given content.
\end{abstract}

Index Terms-Educational document, distance learning, metadata, standards, Semantic Web.

\section{INTRODUCTION}

Most e-Learning applications are accessible via the web and they include varied educational resources that are increasing exponentially. This leads us to searching for relevant documents. These applications share the same relevance searching problems with the web.

Few documents can be reused among the huge number of the educational documents on the web. Finding and selecting a text segment, graphic resources or exercises among others from a document for the goal of reusing it in another or in a new document is almost difficult.

E- Learning is designed for public users who have different levels of knowledge and varied skills. They don't know that the content of the document they have is adapted to their needs.

\section{E-LEARNING}

The European commission defined "E-learning", in 2000, as "the use of new multimedia technologies and the internet to improve the learning quality by making it easy for users to access to resources and services as remote trade collaboration".

In this section, we will present the actors of an eLearning resources used by each actor. We are interested in educational documents are saying essentially exploited by teachers and learners.

\section{A. Actors of an e-learning what?}

For an e-Learning, the main actors are the learners, teachers, administrative staff and technicians [9]. According to the tasks performed by these actors, they use different resources. For example, a technician will need access to documents to manage computers; a secretary will need access to the records of registrations while some resources can be used by these different actors [9].

In this article we focus on the educational resources used by two major actors: teachers and learners.

\section{B. Educational objects}

We are interested in documents known as teaching that are created for the learning use only, among the huge number of documents available on the web. Though

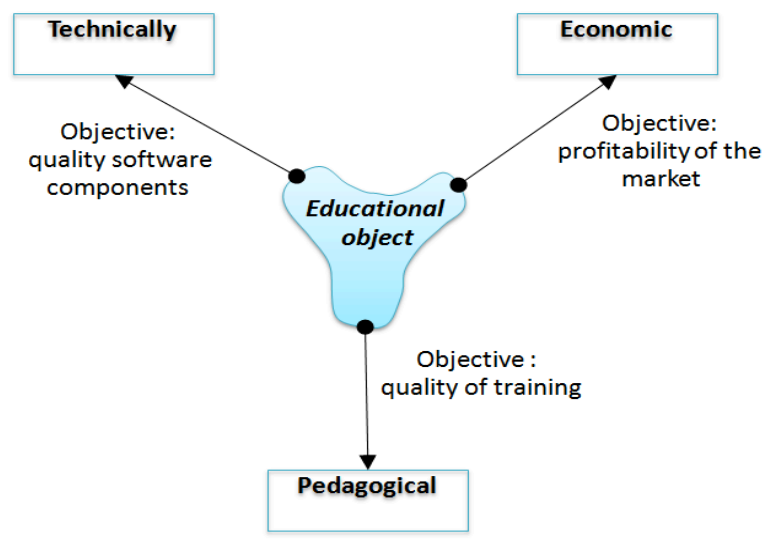

Figure 1. A concept from different points of view [15].

producing these kinds of documents requires significant time and budget, but at the same time it can be recouped only id it's reused all across the wide web. Therefore, it's crucial to structure and index.

Figure 1 illustrates the tensions presented around the concept of learning object..

At the economic level, it is to reduce production costs without reducing quality. This involves having reusable and shareable learning objects.

At the pedagogical level, the ongoing development of training, throughout the life and the installation of individualized courses require to have reusable and especially adaptable learning objects.

Finally on a technical level, the interest of approach by object, broadly put forward in computer development, is not any more to show. It makes possible the reuse of learning objects in numerous contexts.

Curriculum materials become learning objects: a digital entity used in learning environments with the following properties.

- Autonomy: Each learning object used separately from the other

- Reusability: Elementary learning objects can be used in different contexts and for many purposes.

- Aggregation: Learning objects can be grouped and regrouped in order to form other learning objects.

- Indexing: each learning object has a description can be retrievable easily.

In addition, a given learning object should lead to an adequate learning: 
- No superfluous: it must be limited to relevant learning objects if we're in need of just one fraction of required objects.

- At the right time: we can find the learning objects in time relying on the indexation.

- Custom: the ability of customization of courses across an organization or each person or user.

\section{The SEMANTIC Web}

"The semantic web is an extension of the current web in which information is given well-defined meaning, better enabling computers and people to work in cooperation" [7].

In this section, we present the Semantic Web technologies and the needs expressed for the use thereof.

\section{A. Why the semantic web?}

The creation of the web was in the early 90 s in order to facilitate the access and sharing an important volume data on the internet. HTML formed the most important solution for documents formats online [12].

Nowadays, the web contains a wide range of documents, but there is no way to control the content: the current web doesn't offer any services in this sense in a way that the user wastes his/her time in consulting web pages to find what they need.

Because of this problem, the $3 \mathrm{wc}$ (World Wide Web consortium) introduced the semantic web as a solution for the improvement of the web to finally offer the users relevant information. This has made the web resources understandable by human and machines. The $3 \mathrm{wc}$ has begun to build new performance tools and languages. XML, RDF, OWL which Figure 2 exposes the layers of the latter.

By using XML, we could separate content from the presentation. Additionally, RDF has made it easy for us to describe the web resources and finally the OWL has offered the users the opportunity to make arguments.

\section{B. The metadata.}

Tim Berner-Lee said « Metadata is information about web resources (or other) understandable by humans and processable by software $»[12]$.

The importance of this information is that it is treatable by a software in an automatic way. To ensure that metadata is useable for online resources access, it is mandatory both to have a standard for the resource and the producers and users using the same repository. In addition, this standard must be capable of withstanding the possible developments and extensions to accommodate future needs. The Dublin Core has been the best-known standard for indexing digital documents. It also includes information such as "author", "title", etc...

LOM (Learning Object Metadata) is one of the indexing standards of learning objects and it is built on the top of Dublin Core. It also supplies it by adding specific extensions to pedagogy fields [12].

LOM specifies the syntax and semantics of the learning objects and defines the required attributes in order to better describe the learning objects.

The current version of the LOM defines nine categories with a total of 78 items describing a learning object:

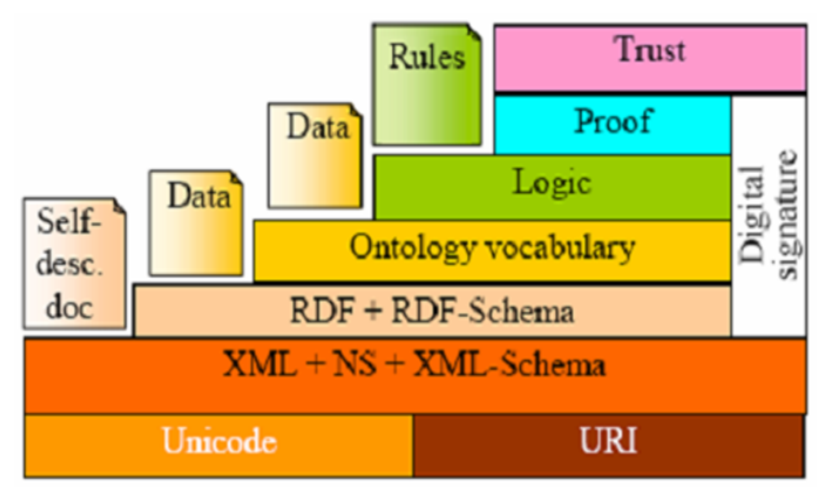

Figure 2. Layers of the semantic web.

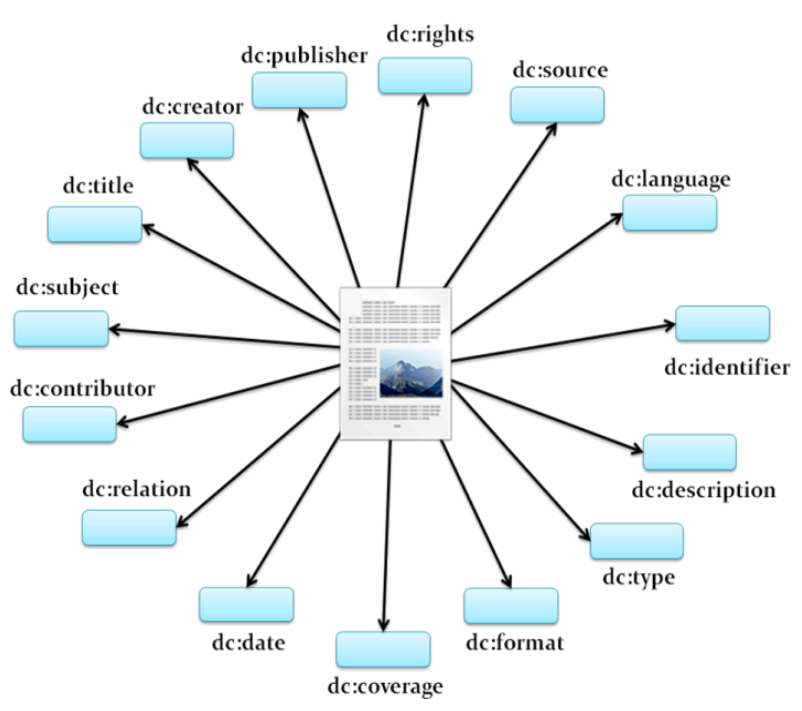

Figure 3. Dublin Core elements.

- General: resource description across as an identifier, title, keywords, etc.. ;

- Life Cycle: description of features on the history of the resource, its life cycle and so on. ;

- Meta-Metadata: description of the learning resource itself as id, contribution, language ... ;

- Technique: Set the techniques, such as data type, format, size, etc..;

- Pedagogy: Teaching characteristics;

- Fees: Costs, copyright, description ... ;

- Relationship: characteristics expressing the links to other resources, such as type (nature of the relationship);

- Annotation: Comments on the educational use of the resource: Author, date, description;

- Classification: characteristics of the resource described by entries in classification systems (purpose, classification references, path ...).

\section{The Semantic Web Contribution in E- LEARNING DOMAIN}

There is an infinite number of documents and services on the internet that are accessible to users, but the majority of these documents and services have a unique organization, presentation and content that satisfy many users, but not all of them. 
The same problem exists as for the e-learning system; our duty is to adapt the instructional content to users' requirements and make it reusable by teachers so that the teachers can build another one.

The E-learning that can grow quickly and benefit from the semantic web solution is among the services that are found on the web.

\section{A. The reuse.}

The formation of educational materials deposits is a great challenge for the well-being and the success of any E-learning project. This implies new teaching materials requirements. In the first place, we believe we should allow these materials to be reused in different contexts by different users. These multi-purpose-operating documents mean that they can be reconfigured for each of these contexts. This reconfiguration is then passed through an adaptation phase [14].

We propose the construction of a warehouse of educational materials which will be composed of two parts:

- The database will store all the learning objects filtered;

- All LOM descriptors and semantic descriptors resulting from the indexing phase.

The LOM and the semantic descriptors will allow us to easily find a learning object stored. So our warehouse will have the structural design depicted in Figure 4.

The two phases of insertion of a learning object are:

- A filtering phase: filtering of relevant educational materials based on a rules engine.

- An annotation phase: it is associated with semantic annotations and descriptors LOM each learning object.

The first purpose of the educational materials repository is that the added documents can be reusable: documents are to be reused in many contexts other than the first contexts if these documents have been made available on the web. The reuse of a document then implies a further formal context for another use. The repository is to enable people to use the added documents in various ways and contexts. We are going to discuss the operating multipurpose [14].

\section{B. Adaptation}

The information fund on the current web are presented in the same manner for all users that is to say the current web doesn't take the needs and interests of these users into consideration or even whether they are really interested in the same information. The web must provide relevant information based on feedback from users for better understanding and proper management of web resources [1].

For better adaptation, the system must:

- Know the users: their needs, their interests, and what they want and don't want.

- Present the diagram of the source: the system must help the user search for a simple way in large amounts of resources.

The adaptation in the semantic web can be applied in both fields.

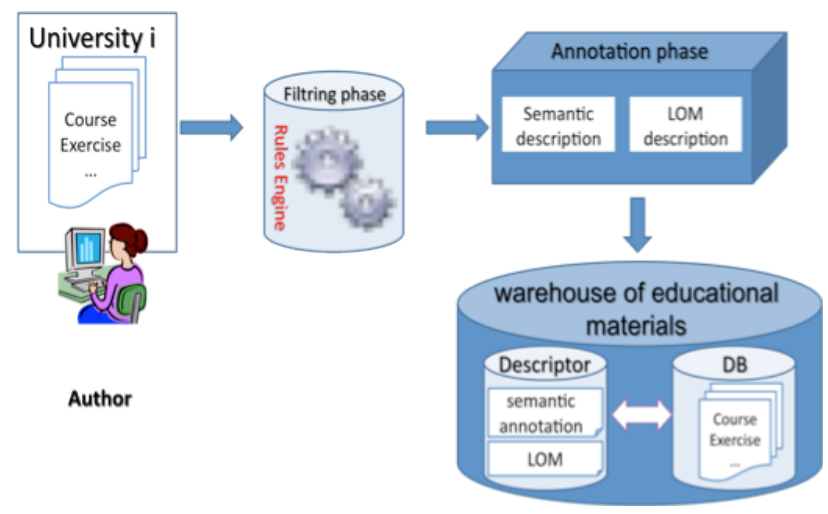

Figure 4. Modeling a warehouse of learning objects [1].

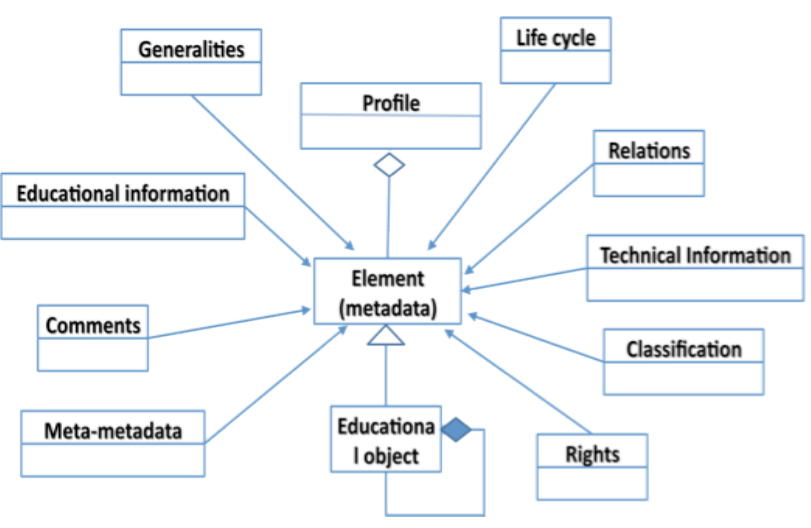

Figure 5. Description of a learning object by LOM [1].

- The adaptive virtual documents: these documents are composed of a set of fragment information and a typesetting system semantic for the selection, assembly and organization of these fragments according to the specifications and goals of learners in the adaptation of the aspect of document users.

- The adaptive hypermedia: we are interested in the adaptation of the hypermedia in our approach; we rely on the notion of a grain of knowledge obtained by the semantic decompositions of learning resources and adaptive multi-agent systems technology.

\section{CONClusion}

In this paper, we understand the importance of learning objects to the transfer of knowledge in e-learning in a way that explains how their production by several actors and their exponential increase in web entails having techniques for finding and selecting a text segment or graphic resources, exercises among others from a document with the aim of reusing it in another or a new document.

The Semantic Web proposes solutions, many of which are interesting in the field of e-Learning.

\section{REFERENCES}

[1] A CHEKRY, A ORICHE, M KHALDI « Sharing and Adaptation of Educational Documents in E-Learning» International Journal of Emerging Technologies in Learning. ISSN: 1863-0383, iJET, Volume 7, No 1 (2012).

[2] A ORICHE, A CHEKRY, M KHALDI, K ELKADIRI « Annotation sémantique des ressources de L'enseignement a distance pour une communauté virtuelle a base d'agents » TELECO2011 \& 7ème JFMMA Mars 16-18, 2011 - Tanger MAROC. 


\section{SHORT PAPER}

[3] B. Steichen, S. Lawless, V. Wade (2009). Dynamic Hypertext Generation for Reusing Open Corpus Content, In the Proceeding HT'09 -20th ACM conference on Hypertext and hypermedia.

[4] D. A. Wiley, (2000). Connecting learning objects to instructional design theory: A definition, a metaphor, and a taxonomy. In D.A. Wiley (Ed.), The instructional use of learning objects.

[5] El. Megder, C. Cherkaoui et D.Mammass, (2008). Towards a design Methodology for an Organizational Memory based on ELearning and ontologies. ICGST-AIML Journal, ISSN: 16874846, Volume 8, Issue III, December 2008.

[6] N Iles, A Chikh, J Mothe «Architecture distribuée d'un entrepôt pédagogique » Septembre 2008.

[7] $\mathrm{T}$ Berners-Lee, James $\mathrm{H}$ Ora Lassila «the semantic web» Scientific American.

[8] A CHIKH, « Une approche méthodologique de réutilisation en ingénierie de document. Application au e-learning », 2003/1-2 Volume 7 ISSN 1279-5127| pages 59 à 88.

[9] M ABEL, Dominique LENNE, C MOULIN et A BENAYACHE, "Gestion des ressources pédagogiques d'une e-formation ", 2003/1-2 - Volume 7, ISSN 1279-5127 | pages 111 à 128.

[10] M Abel ,D Lenne, C Moulin et A Benayache, « Gestion des ressources pédagogiques », UMR CNRS 6599 Heudiasyc Université de Technologie de Compiègne BP 20529F-60206 Compiègne cedex,

[11] M Abel ,D Lenne, C Moulin et A Benayache, "Gestion des ressources pédagogiques d'une e-formation", Document numérique 2003/1-2, Volume 7, p. 111-128.

[12] Y Bourda (2001), "Objets pédagogiques, vous avez dit objets pédagogiques ? ":Supélec, Plateau de Moulon, F-91192 Gif-surYvette CEDEX

[13] A Benayache. Construction d'une mémoire organisationnelle de formation et évaluation dans un contetxe e-learning le projet $\mathrm{Me}$ morae. Thèse de Doctorat, spécialité Informatique, Université de Technologie de Compiègne, 2005.

[14] S CROZAT et E GEBERS., Pratiques documentaires et création de ressources pédagogiques Quel rôle pour les standards ?, Uni- versité de Technologie de Compiègne, Novembre 2007 - ISBN 978-2-9525658-3-7

[15] Pernin J.P., « Objets pédagogiques : unités d'apprentissage, activités ou ressources? »In : Sciences et Techniques Educatives, Hors Série 2003 « Ressources numériques, XML et éducation », 2003, pp. 179-210

\section{AUTHORS}

CHEKRY Abderrahman received the Master degree in software quality in 2009 from Abdelmalek Essaâdi University in Tetwan, Morocco. Currently, he is a PhD Student in Computer Science. He is also member of Network of Researchers in Information Technology and Communication for Education "Réseau de Chercheurs en Technologies de l'Information et de la Communication pour 1'Enseignement" (RES@TICE). Ongoing research interests: Semantic Web and Computing environments for Human Learning "Environnements Informatique pour 1'Apprentissage Humain (EIAH)".

KHALDI Mohamed received the $\mathrm{Ph}$ degree in Information and Communication Technologies in Education "ICTE". Currently he is a Professor of Computer Engineering in Abdelmalek Essaâdi University and he is the vice-director of the "Ecole Normale Supérieure (ENS)" of Martil in Morocco. He has published several articles on Elearning and Semantic Web. He is also part of many boards of international journals and international conferences.

This article is an extended and modified version of a paper presented at the EDUCON2012 conference, held at University Mohammed V Souissi, Morocco in the period 17-20 April 2012. Received 4 November 2012. Published as resubmitted by the authors 18 December 2012. 